\title{
Prevent Depression: Improving Access to Brazil's Mental Health Services
}

\author{
R. Heidt (Ryan Heidt)
}

Health Administration \& Human Resources,

$4^{\text {th }}$ Floor McGurrin Hall, Scranton, PA 18510-4699

\section{E-mail address:}

ryan.heidt@scranton.edu

\section{Reprint address:}

Health Administration \&

Human Resources

$4^{\text {th }}$ Floor McGurrin Hall

Scranton, PA 18510-4699

Suource: Clinical Social Work and Health Intervention

Volume: 7

Issue: 4

Pages: $20-24$

Cited references: 14

\section{Reviewers:}

Prof. Dr. Roberto Cauda, Ph.D.

Institute of Infectious Diseases, Catholic University of the Sacred Heart, Rome, IT

e-mail: roberto.cauda@unicatt.it

Robert J. Spinelli, MBA, MPH, DBA

Undergraduate Health Administration Program Director

e-mail: robert.spinelli@scranton.edu

\section{Key words:}

Depression, Mental health, Psychosocial Community Centers, Burden of disease.

\section{Publisher:}

International Society of Applied Preventive Medicine i-gap

CSWHI 2016; 7(4): 20 - 24; DOI 10.22359/cswhi_7_4_03 @ 2016 Clinical Social Work and Health Intervention

\section{Abstract:}

Brazil consistently ranks as one of the most violent and socially inequitable countries across the globe. Both violence and social inequality are associated with depression, resulting in Brazil having a high prevalence of the disease compared to other countries. Depression leaves a large burden on the residents of Brazil in terms of disability-adjusted life years (DALYs), resulting in higher utilization of healthcare services, more hospitalizations, and lost productivity. Brazil is 
deinstitutionalizing mental health care by utilizing Psychosocial Community Centers (CAPS) to provide mental healthcare to the population. However, there are a lack of centers in lower socioeconomic areas consequently creating a discrepancy in coverage and access to mental healthcare. Other Latin American countries such as Chile and Panama have taken steps to improve access to mental health via integrating primary care and mental healthcare. Brazil can utilize similar ideas, along with better education of primary care staff to improve access to mental healthcare.

\section{Introduction}

When people are free of depression and other psychological issues, they become happier, healthier, and more productive. Today, depression is becoming more of a concern in healthcare. Depression is the $4^{\text {th }}$ leading cause of disability worldwide affecting 350 million people. The World Health Organization suggests that depression will become the $2^{\text {nd }}$ leading cause of disability by 2020 (Kessler \& Bromet 2014). The effect this has on affected individuals includes limited activity and well-being, compromised physical health, functional impairment, and other comorbidities.

\section{Prevalence}

The World Health Organization conducted a study on 12-month prevalence rates of 19 countries across the globe. The sample included in the study was comprised of both developing and developed countries. Of the 19 countries examined, Brazil had the highest 12-month prevalence rate of depression (10.4\%) compared to the average 5.4\% (Kessler et al 2010). It is estimated that Brazilians have a $17 \%$ lifetime prevalence rate of major depressive disorder, with $66 \%$ of the cases occurring in females (Sila et al 2014). This high prevalence is exacerbated by a lack of diagnosis and treatment. It is estimated that only $15.3 \%$ of individuals affected with major depressive disorder are diagnosed and treated for their illness (Fujii et al 2012). This under-diagnosis is largely due to unequal access to care and undertrained primary care staff in mental health screening and detection.

\section{Risk Factors}

The high prevalence rate of depression in Brazil is largely due to the high rate of urbanization. Brazil's urban population is $85 \%$, which is in the top $20 \%$ of all countries worldwide (The World Bank (2016). There needs to be an increase in facilities and infrastructure to accommodate the increase in population in cities. However, this usually does not happen in parallel with the rate of urbanization, resulting in poverty, decreased social support, and an increase in violence, which are all risk factors for depression (Srivastava 2009). Therefore, this high percentage of urban population leads to more individuals at-risk for depression.

\section{Burdens}

Depression puts a significant burden on the residents of Brazil. Burdens due to depression are measured via disability-adjusted life years (DALYs). DALYs are the years of life lost due to premature mortality plus years lost due to disability for people living with a health condition or its consequences (The World Health Organization 2016). DALYs are associated with a decrease in economic production, decrease of quality of life, and an increase in healthcare costs. Mental health disorders account for $21.5 \%$ of all of DALYs in Brazil. Depression is the number one factor for DALYs in women and number seven in men. Depression puts a burden on affected individuals through co-morbidities. Individuals with depression are significantly more likely to have anxiety disorders, drug use disorders, nicotine dependence, sleep problems, among 
many more (Fujii et al 2012). Additionally, individuals with depression are significantly more likely to visit the emergency room and have hospitalizations for any medical condition. It is estimated that in $2011,10.7 \%$ of all the sickness benefits claims in Brazil were due to mental health issues with depression being the main cause (Barbosa-Branco et al 2012).

\section{Healthcare in Brazil}

Healthcare in Brazil is provided through the Family Health Strategy (FHS) and Psychosocial Community Centers (CAPS). The Family Health Strategy is comprised of interdisciplinary teams that consist of physicians, nurses, nurse assistants, and four to six community health agents. These teams provide primary care to specific geographic locations. Because these teams are interdisciplinary, it provides an opportunity to integrate mental health professionals onto these teams; however, these teams still largely focus on primary care. (Macinko \& Harris 2015). Psychosocial Community Centers are teams that provide continuous treatment for individuals with severe and persistent mental disorders. These centers provide clinical care and psychosocial rehabilitation in an outpatient setting, while providing partial hospitalization for more severe cases (WHO-AIMS Report on Mental Health System in Brazil 2007). Some of these centers are open 24 hours a day providing access to diverse care, home visits, and allow access to psychiatric medication. There are approximately 1,500 CAPS centers across Brazil, with most of the centers being located in the south and southeast regions of Brazil (Mateus 2008). This skewed placement of centers results in unequal access to mental healthcare. Unfortunately, the traditional evaluation of CAPS coverage in Brazil is based on the number of centers in the geographic location divided by the population of that area. Therefore, with the 1,500 centers and approximate 200 million population, it is estimated that CAPS cover $63 \%$ of Brazil. However, this ratio does not account for geographic location of centers, ultimately miscalculating the actual coverage of CAPS. For example, the State of Rio Grande do Sul ranks $3^{\text {rd }}$ in CAPS coverage based on this calculation. When examined further, it was estimated that only $51 \%$ of Rio Grande do Sul's population had adequate coverage to mental health and " $43.5 \%$ of the state's inhabitants live in municipalities in which coverage rates are $30 \%$ below expected levels" (Lejderman 2010). The estimate of CAPS coverage is misleading. Many areas that are lower in socioeconomic levels have less access to mental healthcare. The quality of mental health in these regions ultimately depends on the degree of communication and integration between the Family Health Strategy teams and Psychosocial Community Center teams. The cities of Sobral and Petropolis utilize good integration models, in which the Family Health Strategy teams take all non-emergency cases first. The CAPS teams visit the Family Health Strategy teams once a month to act as a source of support. This allows for increased communication and teamwork between the teams, resulting in more appropriate referrals to the CAPS. These cities saw a reduction in hospitalizations by $45 \%$ due to an increased degree of communication between primary care and mental health (The World Health Organization). The ultimate goal of CAPS is to de-institutionalize mental health, therefore decreasing the number of psychiatric inpatient beds. One initiative that aids in decreasing the number of inpatient psychiatric beds is the Return Home Program. This program helps to "reintegrate" individuals back into society and increase social inclusion of individuals with "long histories of hospitalization" (WHO-AIMS Report on Mental Health System in Brazil 2007). This program rewards individuals when they leave the psychiatric hospital by giving them financial incentives that are equivalent to 
$\$ 140$ US dollars. There are approximately 3,000 individuals currently benefiting from the Return Home Program.

\section{Latin America's Mental Health Policy}

When compared to the rest of Latin America, Brazil is on the forefront of de-institutionalizing mental health. There are two other countries in particular that are also succeeding with their initiatives to de-institutionalize mental health: Chile and Panama. Brazil, Chile, and Panama have been able to reduce the average number of psychiatric beds per 100,000 from 24 beds to 9 beds over the last decade in their respective countries. To put that in perspective, the rest of Latin America's average number of psychiatric beds have only decreased from 20 beds to 15 beds over the last decade (Minoletti et al 2012). Chile and Panama have had success of decreasing the number of inpatient psychiatric beds by focusing integrating primary care and mental health. Chile utilizes community mental health centers, similar to that of Brazil, which allows for decentralization and improved local resource allocation. Additionally, Chile implemented the National Depression Detection and Treatment Program, which train primary care physicians on mental health screening and detection techniques. The number of patients in this program has increased by $600 \%$ since 2001 (Minoletti et al 2012). Similarly, Panama trains all nurses and non-physicians in early detection of mental health and provides formal mental health screening training for staff.

\section{Improvements to Brazil's Mental Health Policy}

The World Health Organization has three suggestions in regards to mental health policy: de-institutionalize mental health; integrate mental health into primary care; develop community mental health services (WHOAIMS Report on Mental Health System in Brazil 2007).

Although Brazil is on the forefront of de-institutionalizing mental health and utilizing community mental health services compared to the rest of Latin America, there are many areas of improvement to increase access to these essential services. In particular, the main issue is integrating mental health intro primary care. A big concern is that the Psychosocial Community Centers are primarily located around higher socioeconomic regions. This leaves a discrepancy in mental health care for less wealthy individuals. One solution to mitigate this consequence is to create a model of integration for the primary care teams and mental health teams. Similar to models utilized in Sobral and Petropolis, when these teams work closely together there are improvements in quality of care and more appropriate referrals to the mental health teams. Brazil should also implement a formal training program to train primary care staff on early detection and screening for mental healthcare. This training will allow primary care staff to diagnosis and treat less severe cases, leaving the more severe cases for the Psychosocial Community Centers (Gonçalves et al 2011). Chile and Panama, both of which utilize formalized training in mental health for their primary care staff, have seen improvements in quality of care; an increase in the number of patients being treated for mental health; a decrease in the number of psychiatric inpatient beds. Lastly, it is important that Brazil implement a national database that can better track CAPS coverage and performance evaluations. This national database would help identity further areas for improvement in care while more accurately portraying the current status of mental healthcare throughout Brazil. By utilizing these suggested solutions, access to mental healthcare could improve throughout Brazil. 


\section{Conclusion}

Ultimately, the cost of lost productivity due to depression exceeds the cost of direct treatment. Improving access to mental health services will allow individuals to become healthier, happier, and more productive. The current budget for mental health care is $2.38 \%$ of the health budget (Mental Health Atlas 2011). The World Health Organization suggests that this should increase to $5 \%$ in order to match the size of the burden that depression has in Brazil (WHO-AIMS Report on Mental Health System in Brazil 2007).

\section{References}

1. Barbosa-Branco, A., Bültmann U., Steenstra, I. (2012). Sickness benefits claims due to mental disorders in Brazil: associations in a population-based study. Cadernos de Saúde Pública, 28 (10), 1854-1866.

2. Fujii, R., Goren, A., Annunziata, K. et al (2012). Prevalence, awareness, treatment, and burden of major depressive disorder: estimates from the National Health and Wellness Survey in Brazil. Value in Health Regional Issues, 1, 235-243.

3. Gonçalves, R., Vieira, F., Delgado, P. (2011). Mental health policy in Brazil: federal expenditure evolution between 2001 and 2009. Revistade Saúde Pública, 46 (1), 1-7.

4. Kessler, R., Bromet, E. (2014). The epidemiology of depression across cultures. Annual Review of Public Health, 34, 119-138.

5. Kessler, R., Birnbaum. H., Shahly, V. et al (2010). Age differences in the prevalence and comorbidity of DSM-IV major depressive episodes: Results from the WHO World Mental Health Initiative, Depress Anxiety, 27 (4), 251-364.

6. Lejdman, F. (2010). The fallacy of adequate coverage offered by Psychosocial Care Centers in the state of Rio Grande Do Sul: a comment. Revista de Psiquatria do Rio Grande do Sul, 32 (1), 1-2.

7. Macinko. J., Harris, M. (2015). Brazil's Family Health Strategy-Delivering community-based primary care in a Universal Health System. The New England Journal of Medicine, 372 (73), 2177-2181.

8. Mateus, M. et al (2008). The mental health systems in Brazil: Policies and future challenges. Interntational Journal of Mental Health Systems, 2, 12.

9. Minoletti, A., Galea, S., Susser, E. (2012). Community mental health services in Latin America for people with severe mental disorders. Public Health Reviews. 34.

10. Srivastava, K. (2009). Urbanization and mental health. Industrial Psychiatric Journal, 18 (2), 75-76. The World Bank (2016). Retrieved from http://data.worldbank.org/indicator/SP.URB.TOTL.IN.ZS

11. The World Health Organization (2016). Health statistics and information systems. Retrieved from http://www.who.int/healthinfo/global_burden_disease/metrics_daly/en/

12. Vetkasov, A., Hošková, B., Sobotková, I. 2015: Spolehlivost měření pohybu dolních

13. žeber a brániční mobility radiografickou metodou u osob po poranění míchy. In: Rehabilitácia ISSN 0375-0922, Vol. 52, 2015, No 4, p. 228-235.

14. World Health Organization (2007). WHOAims report on mental health in Brazil. Retrieved from http://www.who.int/mental health/evidence/who_aims_report_brazil.pdf

15. The World Health Organization (n.d.) Integrated primary care for mental health in the City of Sobral. Retrieved from http://www. who.int/mental_health/policy/services/Brazil.pdf World Health Organization (2011). Mental Health Atlas 2011. Retrieved from http://www.who.int/mental_health/evidencel atlas/profiles/bra_mh_profile.pdf? $u=1$ 